\title{
'I Want to Go Home Now': Restraint Decisions for Dementia Patients in Western Australia
}

\author{
Judy Allen and Tamara Tulich*
}

\begin{abstract}
This article examines the current legal framework for restraint of persons with dementia in Western Australian aged care facilities and evaluates it in light of recent developments at the national and international levels. It highlights how the current legal framework fails to adequately protect people with dementia and aged care professionals, and considers options for reform. We argue that the viability of supported decision-making for restraint decisions needs to be carefully considered, and that law reform is necessary to ensure that the best decisions are made, the dignity of dementia sufferers is protected, and that there are safeguards to prevent abuse.
\end{abstract}

\section{INTRODUCTION}

Dementia in the last years of life is the reality for many elderly people and a pressing issue in the planning of health care services in Australia. Dementia is not a specific diagnosis but an umbrella term that describes 'a syndrome associated with more than 100 different diseases that are characterised by the impairment of brain functions, including language, memory, perception, personality and cognitive skills'. ${ }^{1}$ In 2013 an estimated 322,000 people were living with dementia, ${ }^{2}$ with an estimated 29,600 in Western Australia. ${ }^{3}$ This figure is projected to treble over the next 40 years, with 900,000 Australians estimated to be living with dementia in $2050,{ }^{4}$ and nearly 70,000 in Western Australia. ${ }^{5}$ In 2008-2009

* We thank the anonymous reviewers of this journal and Murray Allen for their constructive comments on an earlier draft. All errors of course remain our own.

1 Australian Institute of Health and Welfare, Dementia in Australia (2012) 2 $<$ http://www.aihw.gov.au/publication-detail/?id=10737422958>.

2 Australian Institute of Health and Welfare, Improving Dementia Data in Australia (2014) <http://www.aihw.gov.au/WorkArea/DownloadAsset. aspx?id=60129548887>.

3 Alzheimer's Australia WA, Dementia Statistics (2014) <https://wa.fightdementia. org.au/wa/research-and-publications/reports-and-publications/dementiastatistics>; Deloitte Access Economics had a slightly lower estimate of 26,419 people with dementia in Western Australia in 2013: Deloitte Access Economics, Dementia Across Australia 2011-2050 (9 September 2011) 17.

4 Australian Institute of Health and Welfare, Dementia, above n 1; Australian Institute of Health and Welfare, Improving Dementia Data in Australia: Supplement to Dementia in Australia 2012 (2014) $1<$ http://www.aihw.gov.au/ WorkArea/DownloadAsset.aspx?id=60129548887>.

5 Australian Institute of Health and Welfare, Dementia, above n 1, Ch 2; Deloitte Access Economics, above n 3; Alzheimer's Australia WA, above n 3. 
more than half of the residents in Australian Government subsidised aged care facilities had a diagnosis of dementia. ${ }^{6}$

The prevalence of dementia raises important questions about how the law is responding - and should respond - to the needs of people with behavioural and psychiatric symptoms of dementia. As the cognitive function of dementia sufferers decline, their ability to make decisions will recede and they will need decision-making support to give effect to their will and preferences, and ultimately substituted decision-making by someone empowered to make decisions for them. Families need to know that good and timely decisions are made for the care of their loved ones. Health care providers need to know that they operate in a secure legal framework where sound decisions can be made for the treatment and care of the elderly without the threat of liability. The law should ensure that elderly people with dementia receive high quality care, that their dignity is respected and that they are protected from abuse.

The use of physical and chemical restraints in the care and management of dementia sufferers, in particular, remains contentious. The nature of dementia leads to increasing difficulties in managing the tasks of daily life and can be accompanied by an inability to accept care, the risk of falls, wandering, aggression, an inability to recognise personal boundaries, and disinhibited behaviour. ${ }^{7}$ Where these behaviours cannot be managed they can lead to the person being restrained - for their own safety and/or the safety of others. Restraint can include living in locked care facilities, physical restraint in chairs and beds, and chemical restraint including anti-psychotics and benzodiazepines. ${ }^{8}$ While the use of restraints varies between facilities, a recent study estimates the prevalence of physical restraints in aged care facilities ranges between $12 \%$ and $49 \%$, and approximately $50 \%$ of residents, and $80 \%$ of residents with dementia, receive psychotropic medication. ${ }^{9}$ All these forms of restraint are major

$6 \quad$ Australian Institute of Health and Welfare, 'Dementia among aged care residents: First information from the Aged Care Funding Instrument' (2011) vi <http:// www.aihw.gov.au/WorkArea/DownloadAsset.aspx?id=10737419023>.

$7 \quad$ Australian Institute of Health and Welfare, Dementia, above n 1, 2; Peter V Rabins and David M Blass, 'Dementia' (2014) 161(3) Annals of Internal Medicine ITC1-ITC1; Robert O Morgan et al, 'Modelling Causes of Aggressive Behaviour in Patients With Dementia' (2013) 53(5) The Gerontologist 738.

$8 \quad \mathrm{ABC}$ Lateline reported that $60 \%$ of nursing home residents are on psychiatric drugs with as many as $30 \%$ on powerful anti-psychotics: ABC, 'Families count cost of dementia drugs prescriptions', Lateline, 6 August 2012 (Margot O'Neill) $<$ http://www.abc.net.au/lateline/content/2012/s3569736.htm>. For discussion of the different forms of physical and chemical restraint, see David Evans, 'Physical Restraint and Medical Interventions' in Rhidian Hughes (ed), Rights, Risk and Restraint-Free Care of Older People: Person-Centred Approaches in Health and Social Care (Jessica Kingsley Publishers, 2010) 30; Carmel M Hughes and Kate L Lapane, 'Covert Medication and Chemical Restraint' in Rhidian Hughes (ed), Rights, Risk and Restraint-Free Care of Older People: Person-Centred Approaches in Health and Social Care (Jessica Kingsley Publishers, 2010) 41.

$9 \quad$ Camilla Peisah and Ellen Skladzien, The Use of Restraints and Psychotropic Medications in People with Dementia, Report No 38 (Alzheimer's Australia, 2014) 7-8. 
intrusions on the liberty and dignity of the person, which significantly affect the elderly.

This issue has received increasing attention in Australia since 2008 in the wake of the Australian Government's ratification of the United Nations Convention on the Rights of Persons with Disabilities (CRPD), which recognises the dignity and right to liberty and security of persons with disabilities. ${ }^{10}$ The CRPD provides that State parties shall ensure that persons with disabilities are not deprived of their liberty unlawfully or arbitrarily, and that any deprivation of liberty must be in conformity with the law, the CRPD, and guarantees of international human rights law. ${ }^{11}$ Since then, the issue of restraint and the broader questions of decision-making in relation to people with cognitive disabilities have been considered in a number of parliamentary and law reform inquiries, which are likely to lead to significant changes in the law in all Australian jurisdictions. ${ }^{12}$ In March 2014, Australian disability ministers endorsed

10 United Nations Convention on the Rights of Persons with Disabilities (CRPD) opened for signature 30 March 2007, 999 UNTS 3 (entered into force 3 May 2008). See, eg, Michael Williams, John Chesterman and Richard Laufer, 'Consent versus Scrutiny: Restricting liberties in post-Bournewood Victoria' (2014) 21 Journal of Law and Medicine 641; Anita Smith and Danny Sullivan, 'A New Ball Game: The United Nations Convention on the Rights of Persons with Disabilities and Assumptions in Care for People with Dementia' (2012) 20 Journal of Law and Medicine 28; Yasmin Noone, 'Breaking free from restraint' (2013) Australian Ageing Agenda 48. We note that restraint practices were the subject of attention before this, see, eg: AP Retsas and H Crabbe, 'Restraint: Legal Implications for Aged Care' (1996) 15(1) Australian Journal on Ageing 3; Andrew Restas, 'The Use of Physical Restraints in Western Australian nursing homes' (1997) 34(3) Australian Journal of Advanced Nursing 33; Wei-Wei Wang and Wendy Moyle, 'Physical restraint use on people with dementia: A review of the literature' (2005) 22(4) Australian Journal of Advanced Nursing 46; Kirsten Moore and Betty Haralambous, Barriers to reducing the use of restraints in residential elder care facilities' (2007) 58(6) Journal of Advanced Nursing 532.

11 CRPD, Art 14. The Australian Law Reform Commission (ALRC) noted in its recent report that stakeholders suggested that restrictive practices may, in some cases, amount to torture under the United Nations Convention against Torture and Other Cruel, Inhumane and Degrading Treatment or Punishment, opened for signature 10 December 1984, 1465 UNTS 85 (entered into force 26 June 1987): see Australian Law Reform Commission, Equality, Capacity and Disability in Commonwealth Laws, Report No 124 (2014) 39.

12 Community Affairs References Committee, Parliament of Australia, Care and management of younger and older Australians living with dementia and behavioural and psychiatric symptoms of dementia (BPSD) (2014); Australian Law Reform Commission, Equality, Capacity and Disability in Commonwealth Laws, Discussion Paper No 81 (2014); ALRC, Report No 124, above n 11; Victorian Law Reform Commission, Guardianship, Report No 24 (2012). The National Mental Health Commission has also commissioned a report, to be released in 2015, to identify best practice in reducing and eliminating restraint and seclusion of persons with mental health issues as part of its National Seclusion and Restraint Project: <http://www.mentalhealthcommission.gov.au/our-work/ national-seclusion-and-restraint-project.aspx $>$. The reduction and elimination of restraint and seclusion is a key recommendation of Commission's 2012 and 2013 National Report Cards on Mental Health and Suicide Prevention: National Mental Health Commission, A Contributing Life: the 2012 National Report 
a National Framework for the use and reduction of restrictive practices in the disability services sector, ${ }^{13}$ and the Australian Law Reform Commission (ALRC) recently recommended the development of a national approach for the use of restrictive practices in aged care ${ }^{14}$ The ALRC also recommended a set of National Decision-Making Principles to guide reform to State and federal law regarding individual decision-making. ${ }^{15} \mathrm{In}$ line with international human rights standards contained in the CRPD, the Principles recognise the equal right of adults to make decisions and promote supported, rather than substituted, decision-making models with appropriate and effective legal safeguards. ${ }^{16}$

In Western Australia the restraint of dementia sufferers in aged care facilities is on an uncertain legal footing. In other contexts, such as police powers of arrest, deprivations of liberty are strictly regulated. ${ }^{17}$ In the health context, compulsory detention and treatment of persons with infectious diseases or mental illness is authorised and closely regulated by statute. ${ }^{18}$ In contrast, decisions to confine and restrain elderly people with dementia in Western Australia are made informally by family or health care providers, often without any oversight or clear legal authority. The national developments, together with the enactment of the Mental Health Act 2014 (WA) (MH Act 2014) and the 2013 statutory review of the Guardianship and Administration Act 1990 (WA) (GA Act), provide an environment for reform. This article considers the current law in Western Australia and evaluates it in the light of these developments.

This article begins by outlining the legal framework for the confinement and restraint of persons with dementia in aged care facilities in Western Australia. It identifies uncertainties in the current legal framework, namely who has decision-making authority to move persons with dementia into closed accommodation and to consent to their restraint. We

Card on Mental Health and Suicide Prevention (2012); National Mental Health Commission, A Contributing Life: the 2013 National Report Card on Mental Health and Suicide Prevention (2013).

13 Australian Government, National Framework for Reducing and Eliminating the Use of Restrictive Practices in the Disability Service Sector (2014).

14 ALRC, Report No 124, above n 11, 256 (Recommendation 8-2).

15 Ibid, 64 (Recommendation 3-2).

16 Ibid, ch 3. However, as will be discussed in this article, the ALRC's Principles encourage supported decision-making but do not require the elimination of substitute decision-making regimes, contrary to the Committee on the Rights of Persons with Disabilities, General Comment No 1 (2014): Article 12 Equal recognition before the law, 11th sess, UN Doc CRPD/C/GC/1 (19 May 2014); see also Amita Dhanda, 'Legal Capacity in the Disability Rights Convention: Stranglehold of the Past or Lodestar for the Future?' (2007) 34(2) Syracuse Journal of International Law and Commerce 429; Eilionóir Flynn and Anna Arstein-Kerslake, 'Legislating Personhood: Realizing the Right to Support in Exercising Legal Capacity' (2014) 10(1) International Journal of Law in Context 81.

17 See, eg, the Criminal Investigation Act 2006 (WA); Criminal Code (WA) ss 231, $233,235$.

18 See, eg, the Mental Health Act 1996 (WA) (MH Act 1996); Health Act 1911 (WA). 
acknowledge that the restraint of dementia sufferers may be necessary for their proper care and protection, and that in practice health care providers and families generally regard it as a last resort, and impose restraints reluctantly and appropriately. However, the current legal framework fails to protect people with dementia and aged care professionals who may be exposed to liability. In the final part of this article we evaluate the current framework in Western Australia in the light of the National Decision-Making Principles and consider options for reform. This analysis reveals both the benefits and limitations of supported decision-making in the context of restraint decisions. The move to supported decision-making advances the rights of persons with disabilities, however its viability for restraint decisions needs to be carefully considered. The role of the law should be to ensure that the best decisions are made, that the loss of liberty and dignity is minimised and that adequate safeguards are in place to prevent abuse.

\section{The Legal Framework}

The legal framework for the restraint of dementia patients in aged care facilities comprises State and federal legislation and guidelines, and the common law. Commonwealth approved aged care providers operating in Western Australia - those who receive Commonwealth residential care subsidies - are bound by the Aged Care Act 1991 (Cth). The Aged Care Act stipulates the responsibilities of service providers and enables accreditation standards for the quality of care provided. The User Rights Principles 2014 (Cth), made under the Aged Care Act, articulate the rights of care recipients in residential care. These include the right to the full and effective use of legal rights, to appropriate and quality care, to treatment with dignity and respect, and 'to live in a safe, secure and homelike environment, and to move freely both within and outside the residential care service without undue restriction'. ${ }^{19}$ In 2012, the Commonwealth Department of Health and Ageing updated its guidelines on the use of restraints in residential and community care services. ${ }^{20}$ The Decision-making Tool: Supporting a Restraint Free Environment in Residential Aged Care is designed to assist staff to provide a restraint free environment, and states

19 User Rights Principles 2014 (Cth) Sch 1. See also Barnett and Hayes who argue for the introduction of enforceable statutory rights in the Aged Care Act 1991 (Cth): Michael Barnett and Robert Hayes, 'Not Seen and Not Heard: Protecting Elder Human Rights in Aged Care' (2010) 14 University of Western Sydney Law Review 45.

20 Separate decision-making tools exist for residential and community aged care: Department of Health and Ageing, Decision-Making Tool: Supporting a Restraint Free Environment in Residential Aged Care (2012); Department of Health and Ageing, Decision-Making Tool: Supporting a Restraint Free Environment in Community Aged Care (2012). This article focuses on the restraint of dementia patients in residential aged care and thus will refer primarily to that decisionmaking tool. 
that 'a restraint free environment is seen as a basic human right for all residents living in a residential care setting'. ${ }^{21}$

Although the Commonwealth legislation and regulations govern the provision of aged care services as described above, they do not authorise the restraint of persons within aged care facilities and the authority to do so must be sought elsewhere. Without such authority, care providers are exposed to civil and criminal liability for the restraint and confinement of dementia patients.

The common law has a number of well-developed mechanisms with which a person can challenge the lawfulness of a deprivation of liberty. The writ of habeas corpus provides a remedy against restraint where there is no unlawful authority and can be used to challenge confinement in hospitals and care facilities. ${ }^{22}$ It has been used successfully in Victoria by a person with a mental illness who was found to be unlawfully confined in a residential unit, ${ }^{23}$ and by an elderly woman against an aged care facility, ${ }^{24}$ and has been used recently in New South Wales to challenge the detention of a woman in a mental health facility. ${ }^{25}$

Health care providers who confine patients in locked wards, use physical restraints or administer chemical restraint without lawful authority risk civil liability in an action in trespass. The various forms of civil trespass to the person are important checks on the exercise of authority. Where a person is confined to an aged care facility and has been wholly deprived of their liberty, an action for false imprisonment may lie. Where a person is compliant and does not apparently wish to leave, or is physically incapably of leaving, it could be argued that there is no deprivation of liberty. ${ }^{26}$ That view has been rejected in the United Kingdom where it has been held that a person can be deprived of their liberty even if they are unaware of it, ${ }^{27}$ or if they are unable to understand or object to it. ${ }^{28} \mathrm{~A}$ benevolent intention does not change the objective nature of the deprivation of liberty. ${ }^{29}$ Physical restraint in beds and chairs, and chemical restraint, are within the scope of the action in battery. There will be no liability in civil law, however, where there is statutory authority or a valid consent.

The various forms of restraint also engage a number of criminal offences including unlawful assault. ${ }^{30}$ It is also an offence under s 337

$\overline{21 \text { Department }}$ of Health and Ageing, Residential Decision-Making Tool, above n 20, 1.

$22 R v$ Bournewood Community and Mental Health NHS Trust; Ex $p$ L [1999] AC 485 .

23 Antunovic v Dawson [2010] VSC 377.

24 Skyllas $v$ Retirement Care Australia (Preston) Ltd [2006] VSC 409.

$25 \quad$ White $v$ Local Health Authority [2015] NSWSC 417.

26 Rochdale Metropolitan Borough Council v KW [2014] EWCOP 45.

27 Murray v Ministry of Defence [1988] 1 WLR 692.

28 HLv United Kingdom (2004) 40 EHRR 761; Surrey County Council v P; Cheshire West and Chester Council v P [2014] UKSC 19. Surrey County Council v P; Cheshire West and Chester Council v P [2014] UKSC 19. 
of the Criminal Code (WA) to assume custody of or detain a person with mental illness or mental impairment otherwise than in compliance with Western Australia's mental health legislative framework or the law relating to mental impairment. ${ }^{31}$

There are a number of uncertainties in the application of both the common law causes of action and the offences in the Criminal Code to the restraint of people with dementia. These uncertainties are examined below.

\section{Substituted Decision-Making In Western Australia}

The civil action in trespass and the related criminal offences provide a cause of action where a person is deprived of their liberty or subject to bodily interference such as unwanted medical treatment. However, restraint will be lawful if valid consent is given by the individual or someone empowered to make decisions for them. Substitute decision-making may be in the form of judicial intervention or guardianship, and is characterised by the removal of legal capacity from a person and the appointment of another person - the substituted decision-maker - to make decisions in the objective best interests of the affected person. ${ }^{32}$

The parens patriae jurisdiction of courts can be exercised to protect vulnerable members of society who are unable to protect themselves. This welfare jurisdiction includes ensuring that they receive proper medical care. ${ }^{33}$ This jurisdiction is broad and has been held to include authorising the indefinite detention of a person for their protection, ${ }^{34}$ and authorising the administration of anti-psychotic drugs. ${ }^{35}$ It is clear that the Supreme Court could exercise its parens patriae jurisdiction to authorise the restraint of a dementia sufferer, but this is clearly not a practical way to deal with the growing number of people for whom restraint will be considered.

In practice, these decisions are being made by guardians and family members in collaboration with health care providers, but the lawful authority to do so is uncertain. To ascertain the legal status of these decisions two questions must be considered:

- Who has a decision-making power in relation to a person? and

- Does that power include the power to consent to various forms of restraint?

$31 \quad$ Criminal Code s 337.

32 Committee on the Rights of Persons with Disabilities, above n 16; Flynn and Arstein-Kerslake, above n 16.

33 Northridge v Central Sydney Area Health Service [2000] NSWSC 1241.

34 Director-General, Department of Community Services v Thomas [2009] NSWSC 217; In Re K (A child) (Secure Accommodation Order: Right to Liberty) [2001] 2 WLR 1141.

$35 \quad$ Re R (a minor) [1992] Fam 11; [1991] WLR 592 (CA). 


\section{Who Has Decision-Making Power?}

Each State and Territory in Australia has its own statutory framework for decision-making for people who are cognitively impaired. In Western Australia the GA Act gives decision-making power to a hierarchy of substituted decision-makers who can make decisions for people who do not have legal decision-making capacity.

The GA Act reflects a philosophy of maximising autonomy by prioritising, first, a person's own decisions recorded in an advance directive and, secondly, decisions made by a substitute decision-maker chosen and appointed by the person themselves, called an enduring guardian. ${ }^{36}$ These statutory devices to extend self-determination beyond the loss of capacity are still new in Western Australia and, although no data is available, they do not yet appear to be exercised by many people.

For most people with dementia the restraint decisions are being made by family members in conjunction with health professionals. Commonly there is no formal appointment of an enduring guardian or a guardian. In those circumstances the GA Act gives listed family members and other persons 'responsible' the power to make treatment decisions when the person is unable to make reasonable judgments about treatment. ${ }^{37}$ If there is a 'responsible person' then there will not generally be a need for a guardian as required by s 44 of the Act. Where there is no 'responsible person' available, or where there are disputes between family members, then the State Administrative Tribunal will appoint a guardian who can be given powers to make health care and accommodation decisions. ${ }^{38}$ Where a guardian with the relevant powers is appointed, then their decision will have priority over that of a 'responsible person' ${ }^{39}$

The GA Act provides a clear hierarchy of decision-making for people with impaired decision-making capacity. However, questions remain as to whether the decision-making powers conferred on these decision-makers extend to decisions about confinement in closed accommodation or about physical or chemical restraint.

\section{Closed Accommodation And Substitute Decision-Making}

One of the most distressing stages in the decline of dementia sufferers comes when they are no longer able to remain in their own home and are moved to locked accommodation and care facility. The move is often vehemently resisted by the person and that distress is very painful for family members. The move to closed accommodation is usually a complete and final loss of liberty for the person. This loss of liberty is both such a familiar scenario and such a serious matter that one would think that the

$36 \quad$ Guardianship and Administration Act 1990 (WA) s 110ZJ.

37 Ibid, s 110ZD.

38 Ibid, s 45.

39 Ibid, s 110ZJ. 
law would be clear as to who can make this decision and in what circumstances. Sadly this is not the case in Western Australia. Some jurisdictions do have legislative regimes that deal clearly with this issue,$^{40}$ however, Western Australia is not alone in failing to address this uncertainty.

The decision to move the dementia sufferer into locked accommodation is usually made, de facto, by family members who self-identify as 'next of kin'. It is doubtful, however, that they can lawfully make this decision. At common law, next of kin had no powers to make decisions for adult members of the family with a decision-making incapacity. The only relevant powers are those conferred by the GA Act.

The powers of responsible persons under s 110ZD are confined to treatment decisions. ${ }^{41}$ 'Treatment' includes medical or surgical treatment, dental care or other health care. ${ }^{42}$ The contentious question is whether a decision that a dementia patient move to a locked accommodation is a 'treatment' decision. This is a multiple decision that involves the location of accommodation, the choice of a provider of personal and health care and a decision to remove the person's liberty. ${ }^{43} \mathrm{~A}$ decision that a person move house is clearly not a treatment decision that can be made by the responsible person, however, if this is regarded as predominantly a choice of a health care provider and the location at which the care will be provided then it could be regarded as a decision about 'health care'. However, a decision to confine a person in a locked facility differs from other admissions to hospital or to a care facility because it involves the long term and complete deprivation of liberty. In MMv Mental Health Review Board, Scott $J$ concluded that detention in an authorised hospital to ensure that MM, who had dementia, was properly housed, fed and clothed amounted to 'treatment' under the compulsory treatment provisions of the Mental Health Act 1996 (WA) (MH Act 1996). ${ }^{44}$ The MH Act 1996 establishes limits and extensive oversight of detention decisions, in stark contrast to the informal exercise of powers by a responsible person under the GA Act. Legislation that interferes with liberty should be strictly construed, ${ }^{45}$ and courts will not impute an intention to the legislature to abrogate or interfere with fundamental human rights in the absence of express statutory language. ${ }^{46}$ We would argue that 'treatment' under the GA Act, where there is no provision for oversight, should not be interpreted in the same way.

40 See, eg, Guardian and Administration Act 2000 (Qld) Ch 5B; Ministry of Justice (UK), Deprivation of Liberty Safeguards: Code of Practice to Supplement the Main Mental Capacity Act 2005 Code of Practice (TSO, 2008) 9-10; Long Term Care Homes Act, SO 2007 (Ontario).

41 Guardianship and Administration Act 1990 (WA) s 110ZD(1).

42 Ibid, s 3.

43 In White $v$ Local Health Authority [2015] NSWSC 417 admission to a mental health facility was regarded as an accommodation decision.

$44 \quad$ MM v Mental Health Review Board [1999] WASC 1005.

45 Ibid.

46 See, eg, Re Bolton (1987) 162 CLR 514, 523 (Brennan J); Dan Meagher, 'The Common Law Principle of Legality in the Age of Rights' (2011) 35 Melbourne University Law Review 449. 
The powers that can be given to an enduring guardian, or a guardian appointed by the State Administrative Tribunal, are wider and go beyond treatment decisions, but once again it is unlikely they include making a decision which indefinitely deprives the represented person of their liberty. A guardian given plenary powers has the same functions as someone given parental responsibility by a parenting order under the Family Court Act 1997 (WA) as if the represented person was a child lacking in mature understanding. ${ }^{47}$ Although a parent has power to restrict liberty to some extent, indefinite confinement or restraint is beyond the powers of a parent. In Director-General, Department of Community Services $v$ Thomas $^{48}$ Brereton J, of the Supreme Court of New South Wales, accepted that the indefinite confinement of a 15 year old was beyond the scope of parental responsibility. If this view is accepted, then a plenary guardian does not have the power to make a decision that the represented person be confined in locked accommodation. This apparently is not the view taken by the Victorian Law Reform Commission, which assumes, without citing authority, that guardians appointed under the Victorian legislation, which has similar provisions to the GA Act, can be given authority to authorise accommodation in a locked facility. ${ }^{49}$

An administrator, or the donee of an enduring power of attorney, may have the power to enter into a contract for the provision of accommodation and care on behalf of a represented person or the donor, but it is clear that neither has the power to make a decision as to where the represented person will live. This is a personal decision that is beyond the powers of an administrator or an attorney, which are confined to managing the estate of the represented person..$^{50}$

\section{Physical and Chemical Restraint and Substitute Decision-Making}

The use of physical and chemical restraint of dementia sufferers in care facilities raises similar difficulties in terms of substitute decision-making. Once again the power of a 'responsible person' depends on the definition of treatment. It is arguable that restraint could be 'medical treatment' and 'health care' where it is to prevent a patient causing themselves harm. ${ }^{51}$ In $B C B$ the WA Guardianship Board held that the question had to be

$47 \quad$ Guardianship and Administration Act 1990 (WA) s 45(1).

48 Director-General, Department of Community Services v Thomas [2009] NSWSC 217; cf Re Inaya [2007] FamCA 658. The Family Court has power to determine what is a parental responsibility.

49 Victorian Law Reform Commission, above n 12, 15.14; Guardianship and Administration Act 1986 (Vic) s 24. Cf Guardianship Act 1987 (NSW) ss 21, $21 \mathrm{~A}$ - where a guardian has custody of the person under guardianship and can be given powers to ensure that the person under guardianship complies with the decisions of the guardian.

50 Guardianship and Administration Act 1990 (WA) s 69.

$51 \quad B v$ Croyden Health Authority [1995] 2 WLR 294. 
considered on a case by case basis and would depend on the reasons for its use, the purpose for which it would be put and who prescribed its use. ${ }^{52}$ Another relevant factor could be the temporal extent of the restraint. Where it is effectively continuous it may be less likely to be regarded as health care.

It is likely that the broader powers that can be given to guardians and enduring guardians may extend to the temporary use of restraint to protect the person from harm. It appears to be accepted that parental powers can include temporary restraint. ${ }^{53}$ Where the restraint is effectively continuous, however, there are once again doubts that it is within parental powers and hence within the powers that can be given to guardians. This lack of certainty is unlikely to promote the best decision-making for dementia sufferers.

The defence of necessity has been used in the past to justify medical care without consent..$^{54}$ Necessity was only ever applicable, however, where there was no decision-maker available. Where legislation such as the GA Act provides a hierarchy of substitute decision-makers then it has no remaining application in non-urgent situations. In an emergency situation, s 110ZI of the GA Act gives health professionals a limited authority to provide treatment, which may extend to temporary restraint.

\section{Statutory Authority for Restraint in Western Australia}

There is no express statutory authority for restraint of persons in a health context in Western Australia, apart from the compulsory detention and treatment regimes contained in the MH Act 1996 and the Health Act 1911 (WA) ${ }^{55}$ A person with dementia and behavioural and psychiatric symptoms of dementia may meet the definition of a mentally ill person under the $M H$ Act 1996, which includes people who suffer from 'a disturbance of thought, mood, volition, perception, orientation or memory that impairs judgment or behaviour to a significant extent'. ${ }^{56}$ This definition is largely replicated in the $M H$ Act $2014,{ }^{57}$ and may well encompass many people with dementia. ${ }^{58}$ Indeed, the Explanatory Memorandum to the

$52 B C B$ [2002] WAGAB 1. This decision was made before the 2010 amendments to the definition of 'treatment' but the amendments are unlikely to alter the approach adopted.

53 Director-General, Department of Community Services v Thomas [2009] NSWSC 217.

54 Re F (Mental Patient: Sterilisation) [1990] 2 AC 1.

55 The Mental Health Act 2014 (WA) (MH Act 2014) was passed in October 2014 and repealed and replaced the Mental Health Act 1996 (WA) on commencement (commenced on 30 November 2015 following a 12-month trial implementation). Our discussion will, where relevant, refer to both pieces of legislation.

56 Mental Health Act 1996 (WA) s 4.

57 Mental Health Act 2014 (WA) s 6.

58 See discussion in MMv Mental Health Review Board [1999] WASC 1005 (Scott $J)$. In that case, it was conceded by the parties that the appellant, who suffered 
Mental Health Bill 2013 (WA) stated that 'dementia may constitute a mental illness if the requirements' of the definition are met. ${ }^{59}$ However, the mental health legislation only authorises involuntary detention and restraint of persons with mental illness in authorised hospitals. ${ }^{60}$ It does not provide authority for a person to be detained or restrained in an aged care facility. Therefore, aged care providers who restrain or detain persons with dementia, who also meet the definition of a mentally ill person, are operating outside of the mental health legislation and are exposed to criminal liability. The statutory immunity contained in the MH Act 2014 will, when proclaimed, provide age care providers with some protection; however, it does not extend to physical or mechanical restraint and uncertainty remains as to the scope of the immunity.

\section{A Criminal Liability}

As the law currently stands in Western Australia, health care providers who detain dementia patients risk prosecution under s 337 of the Criminal Code. Section 337 makes it an offence to detain - or assume custody of - a person suffering from a mental illness otherwise than in compliance with the provisions of the MH Act 1996 (or the MH Act 2014 upon its commencement). ${ }^{61}$ Aged care providers cannot operate in compliance with mental health legislation as they are not authorised hospitals and do not follow the prescribed assessment, detention and review procedures. Therefore, if a dementia patient has a mental illness as defined by the mental health legislation, an aged care provider who detains them can be criminally liable.

from dementia, met the first part of the definition. Scott J considered, on appeal, whether the Board turned its mind to the second part of the definition, not whether the second part could be met by a person with a dementing illness. We note that the question of whether dementia is a 'mental illness' for the purposes of mental health legislation has been answered differently in Australian States and Territories. In Queensland, in Re HHR [2012] QMHC 15, Ann Lyons J found dementia to be a mental illness as defined by the Mental Health Act 2000 (Qld); In Victoria, the Mental Health Review Board held, in 02-102 [2002] VMHRB 1 , that the patient suffered from 'the mental illness of dementia' satisfying the relevant definition in the Mental Health Act 1986 (Vic). By contrast, in NSW, Powell $\mathrm{J}$ held that senile dementia is not a mental illness as defined by the Mental Health Act 1958 (NSW) in RAP $v$ AEP [1982] 2 NSWLR 508; the NSW Law Reform Commission recently stated that dementia is unlikely to meet the definition of a mental illness in the Mental Health Act 2007 (NSW): NSW Law Reform Commission, People with cognitive and mental health impairments in the criminal justice system: Diversion, Report 135 (2012) [5.92]-[5.93]; see also Stephen Ticehurst, 'Is dementia a mental illness?' (2001) 35 Australian and New Zealand Journal of Psychiatry 716.

59 Explanatory Memorandum, Mental Health Bill 2013 (WA) 5.

60 Mental Health Act 1996 (WA) Div 4; Mental Health Act 2014 (WA) s 4, Div 4.

61 Section 50 of the Mental Health Legislative Amendment Act 2014 (WA) provides for consequential amendment to s 337 of the Criminal Code on the proclamation of the Mental Health Act 2014 (WA). 


\section{B Statutory Immunity}

The exposure of aged care facilities to criminal liability under s 337 of the Criminal Code was noted in the Holman Report, ${ }^{62}$ a statutory review of the MH Act 1996 conducted in 2002-2003. Holman recommended that the Criminal Code be amended to exclude from liability a person who, in caring for a person with a degenerative brain disease, prevents them from wandering and therefore harming themselves. ${ }^{63}$ The then government accepted this recommendation; however, changes were not made until the passage of the $M H$ Act 2014 in October $2014 .^{64}$

Section 584 of the $M H$ Act 2014 provides immunity from criminal and civil liability where:

- A person has 'lawful charge of a person and in good faith detains, or continues the detention of the person ... to prevent that person from leaving a particular place'; and

- The person detained 'has or is reasonably suspected of having a mental illness'; and

- The person detained 'does not have the capacity to decide whether or not to withdraw himself or herself from that lawful charge'. ${ }^{65}$

The Explanatory Memorandum to the Mental Health Bill 2013 (WA) provided the following commentary on cl 580, which became s 584 of the MH Act 2014: ${ }^{66}$

Clause 580 provides a defence against a charge of deprivation of liberty where, for example, an elderly person with dementia is prevented from wandering and putting themselves at risk, by the door of a psychogeriatric ward being locked (not all psychogeriatric wards are authorised hospitals), and the bodily restraint provisions in Part 14 only apply to authorised hospitals. The clause 580 defence is limited and does not include restraining the person if the person attempts to leave. In those situations a common law duty of care may be relied upon in some circumstances.

While addressing the concerns raised by Holman, this provision is problematic. It is unclear, for example, what constitutes 'lawful charge of a person' for the purposes of s 584(1). In particular, it is unclear whether the informal admission of a dementia patient to a locked ward, which we argue lacks solid legal basis, places an aged care facility in 'lawful charge' of a person.

62 D'Arcy Holman, The Way Forward: Recommendations of the Review of the Mental Health Act 1996 (2003) [3.9].

63 Ibid.

64 The review of the Mental Health Act 1996 (WA) was a decade long process culminating in the passage of the Mental Health Act 2014 (WA). For the government's acceptance of Holman's recommendation see: Government of Western Australia, The Way Forward for Mental Health Legislation in Western Australia Report on the Review of the Mental Health Act 1996: The Government's Response to the Review's Recommendations (2004) [6.9].

65 Mental Health Act 2014 (WA) s 584(1)-(2).

66 Explanatory Memorandum, Mental Health Bill 2013 (WA) 127. 
Section 584(1)(b) further requires that the person lack 'the capacity to decide whether or not to withdraw himself or herself from that lawful charge'. The Act provides some guidance on decision-making capacity: including a presumption of decision-making capacity for adults and prescribing the test for determining capacity to make decisions. ${ }^{67}$ In particular, s 15 provides that a person has the capacity to make a decision where she or he has the capacity to understand information provided about the decision, the matters involved in the decision and effect of it, is able to weigh up these factors for the purpose of making the decision and communicate the decision. Section 15 reflects the common law, which sets a high bar for decision-making capacity, in particular because of the requirement to weigh up the information, matters involved in and effect of the decision. ${ }^{68}$

Importantly, s 584 does not sanction the use of bodily restraints, nor exclude from liability those employing them. ${ }^{69}$ The immunity therefore does not extend to: ${ }^{70}$

- Physical restraint by 'the application of bodily force to the person's body to restrict the person's movement'; or

- Mechanical restraint by 'the application of a device (for example a belt, harness, manacle, sheet or strap) to a person's body to restrict the person's movement'.

However, the immunity does include: ${ }^{71}$

- Physical restraint merely to provide "physical support or assistance reasonably necessary - (a) to enable the person to carry out daily living activities; or (b) to redirect the person because the person is disorientated'.

- 'The appropriate use of a medical or surgical appliance in the treatment of a physical illness or injury'; and

- 'The appropriate use of furniture that restricts a person's capacity to get off the furniture'.

It is unclear whether the provision also excludes liability for the imposition of chemical restraints, a concern raised by the Mental Health Law Centre. ${ }^{72}$ This gives rise to further questions about the distinction between restraint and detention, and in particular whether sedation, which can prevent a person 'from leaving a particular place', can constitute detention.

When proclaimed, s 584 will afford protection to care providers who act in good faith to prevent a person with mental illness, or suspected of having mental illness, from leaving a particular place. However, this

$67 \quad$ Mental Health Act 2014 (WA) ss 13, 15.

68 Ibid, s 15(d).

69 Ibid, s 584(3), s 227.

70 Ibid, s $227(2),(4)$.

71 Ibid, s 227(3), (5).

72 Sandra Boulter, Mental Health Law Centre WA, 'Mental Health Bill 2013 still has room for improvement' Briefing Notes for Members of the Legislative Council (12 August 2014). 
provision does not contain safeguards or protections for persons being so confined. While the writ of habeas corpus remains an important protection for those being detained in aged care facilities, this is neither an accessible nor practical avenue for the elderly in aged care facilities.

\section{Protection of Decision-Making in Western Australia}

The current frameworks for decision-making for people with cognitive disabilities are being reconsidered in Australia in the light of the government's ratification of the CRPD, which includes the right, contained in Art 12 , to 'enjoy legal capacity on an equal basis with others'. ${ }^{73}$ The ALRC recommends that States and Territories review their decision-making frameworks to ensure they are consistent with its National DecisionMaking Principles, which reflect the CRPD. ${ }^{74}$ In this section we consider the Western Australian legislation in the light of these principles and their application to decisions about restraint. ${ }^{75} \mathrm{We}$ argue that there are benefits and limitations to supported decision-making in the context of restraint decisions. While supported communication can lead to restraintfree outcomes and minimise loss of dignity, the declining cognitive ability of dementia sufferers means they will ultimately require representative decision-making of some kind.

The National Decision-Making Principles reflect international human rights standards contained in the CRPD, namely the promotion of supported rather than substituted decision-making, and recognition of the dignity and autonomy of persons with disabilities. The National Decision-Making Principles are designed to ensure that: ${ }^{76}$

- Supported decision-making is encouraged;

- Representative decision-makers are appointed only as a last resort; and

- The will, preferences and rights of persons direct decisions that affect their lives.

The Principles recognise that 'all adults have an equal right to make decisions that affect their lives', and that supported decision-making must be accompanied by appropriate and effective legal safeguards. ${ }^{77}$ The Principles are supported by Guidelines that outline criteria on what should be incorporated into legislative arrangements to give effect to the Principles. ${ }^{78}$

73 CRPD Art 12.

74 ALRC, Report No 124, above n 11, 64.

75 Ibid, 274.

76 Ibid, 64.

77 Ibid, Principles 1 (The equal right to make decisions) and 4 (Safeguards).

78 Namely the Support Guidelines, Wills, Preferences and Rights Guidelines, and Safeguards Guidelines, Ibid, 69-88 (Recommendations 3-2, 3-3, 3-4). 
While the Principles reflect the CRPD in their encouragement of supported decision-making regimes, they do not accord with the Committee on the Rights of Persons with Disabilities recent interpretation of Art 12. ${ }^{79}$ There has been uncertainty - both in the literature, ${ }^{80}$ and in the reports of State parties to the Committee ${ }^{81}$ - as to whether the CRPD permits substitute decision-making at all. To clarify the obligations placed on State parties, the Committee has recently restated that States must review their guardianship laws and replace substitute decision-making regimes with supported decision-making regimes. ${ }^{82}$ The Committee further stated that the 'development of substitute decision-making systems in parallel with the maintenance of substitute decision-making regimes is not sufficient to comply with article 12 of the Convention'. ${ }^{83}$ Australia has, however, maintained the view that substitute decision-making will remain necessary as a last resort where a person is unable to make decisions even with support. ${ }^{84}$

The ALRC has argued that the focus should not be on 'substituted versus supported decision-making', but on the limits and standards that apply to representative decision-making. ${ }^{85}$ Where representative decisionmaking is required, the representative must give effect to the person's wills and preferences, or likely wills and preferences. ${ }^{86}$ That accords with the Committee's assertion that it is only by replacing the 'best interests' paradigm of substitute decision-making with the 'wills and preferences' paradigm of supported decision-making that persons with disabilities can enjoy equal legal capacity. When the will and preferences of a person can not be determined, "the "best interpretation of will and preferences" must

79 CRPD Art 12; Committee on the Rights of Persons with Disabilities, above $\mathrm{n} 16$.

80 See, eg, Dhanda, above n 16; Flynn and Arstein-Kerslake, above n 16; Tina Minkowitz, 'Abolishing Mental Health Laws to Comply with CRPD' in Bernadette McSherry and Penny Weller (eds), Rethinking Rights-Based Mental Health Laws (Hart Publishing Ltd, 2010) 151; Nandini Devi, Jerome Bickenbach and Gerold Stuck, 'Moving towards substituted or supported decision-making? Article 12 of the Convention on the Rights of Persons with Disabilities' (2011) 5 ALTER, European Journal of Disability Research 249; Bernadette McSherry, 'Legal Capacity under the Convention on the Rights of Persons with Disabilities' (2012) 20 Journal of Law and Medicine 22; Piers Gooding, 'Supported Decision-Making: A Rights-Based Disability Concept and its Implications for Mental Health Law' (2013) 20(3) Psychiatry, Psychology and Law 431.

81 Committee on the Rights of Persons with Disabilities, above n 16.

82 Ibid.

83 Ibid.

84 Convention on the Rights of Persons with Disabilities: Declarations and Reservations (Australia), opened for signature 30 March 2007, 999 UNTS 3 (entered into force 3 May 2008). See also: Smith and Sullivan, above n 10; McSherry, 'Legal Capacity', above n 80; Bernadette McSherry, 'Mental Health Laws: Where to From Here? (2014) 40(1) Monash University Law Review 175; Penny Weller 'Supported Decision-making and the Achievement of Non-discrimination: The Promise and Paradox of the Disabilities Convention' (2008) 26(2) Law in Context 85. 
guide decision-making'. ${ }^{87}$ This approach is adopted in Bach and Kerzner's facilitated decision-making model of supported decision-making. ${ }^{88}$ Under a facilitated decision-making model, a person is appointed to make a decision that promotes the will and preferences of a person, as best as they can be ascertained, rather than the objective best interests. ${ }^{89}$

The decision-making framework established by the GA Act does not reflect the CRPD or meet the standards of the National Decision Making Principles. The GA Act adopts the binary approach to decision-making reflected in the common law whereby the right to decision-making is dependent on capacity. This all or nothing approach is criticised for completely denying some people the right to exercise legal capacity. ${ }^{90}$ The concept of functional capacity at common law requires that the person can understand and retain information relevant to the particular decision, use the information and weigh it to make a decision. ${ }^{91}$ What is required is the capacity to undertake this process of rational decision-making - not that the decision made is 'reasonable'. ${ }^{92}$ Capacity can vary over time and must be assessed in relation to the particular decision contemplated. The GA Act provides that an advance directive becomes operative and that an enduring guardian or a 'responsible person' can exercise decision-making powers when the person is 'unable to make reasonable judgments'. ${ }^{93}$ In spite of the reference to 'reasonable judgments', which might lead to a focus on outcomes, this has been interpreted as being a capacity test equivalent to the common law test of functional capacity with the focus on the ability to make reasonable decisions. ${ }^{94}$ This capacity test operates as a bright line that completely removes decision-making power from the person and is regarded as contrary to the CRPD assertion of a universal right 'to enjoy legal capacity on an equal basis'. ${ }^{95}$

The criteria for appointment of a guardian under the Act go further and are not dependent on the person having lost decision-making capacity. ${ }^{96}$ Although one of the criteria for the appointment of a guardian is the

87 Committee on the Rights of Persons with Disabilities, above n 16.

88 Michael Bach and Lana Kerzner, A New Paradigm for Protecting Autonomy and the Right to Legal Capacity (Law Reform Commission of Ontario, 2010).

89 Committee on the Rights of Persons with Disabilities, above n 16; Flynn and Arstein-Kerslake, above n 16, 129-130.

$90 \quad$ Flynn and Arstein-Kerslake, above n 16.

91 Re MB [1997] 2 FLR 426; Re C (Adult: Refusal of Medical Treatment) [1994] 1 All ER 819.

92 St George's Healthcare NHS Trust v S [1998] 3 All ER 673.

93 Guardianship and Administration Act 1990 (WA) ss 110F, 110ZD(1).

94 FS [2007] WASAT 202; XYZ v State Trustees Ltd [2006] VSC 444; Dhanda, above n 16 .

95 CRPD Declarations and Reservations (Australia), above $\mathrm{n} 84$, Art 12; Committee on the Rights of Persons with Disabilities, above n 16; Dhanda, above n 16; Flynn and Arstein-Kerslake, above n 16.

96 Guardianship and Administration Act 1990 (WA) s 43(1), provides that the State Administrative Tribunal may appoint a guardian where the person:

(a) has attained the age of 18 years;

(b) is - 
capacity criterion, that the person is 'unable to make reasonable judgments in respect of matters relating to his person', this is not essential. It is enough if the person is 'incapable of looking after his own health and safety' or 'in need of oversight, care and control in the interests of his own health and safety or for the protection of others' ${ }^{97}$ These protective criteria are more restrictive of autonomy than the test of functional competence, which limits valid decision-making at common law, ${ }^{98}$ and enable the person's own decision-making power to be taken away from them in their own interests as well as to protect others. This appears to be contrary to the first National Decision-Making Principle, which provides that persons with disability have 'an equal right to make decisions that affect their lives and to have those decisions respected' ${ }^{99}$ An equal right to make decisions includes the right to make bad or unreasonable decisions.

The GA Act provides some protection of autonomy by adopting a presumption of capacity, ${ }^{100}$ giving priority to the person's own decisions, ${ }^{101}$ and requiring the adoption of the least restrictive options. ${ }^{102}$ However, to meet the aspirations of the National Decision-Making Principles and international human rights standards, the capacity test will need to be reframed to promote supported decision-making and to ensure that a person who is able to make a decision with appropriate support is not denied the right to make their own decisions. ${ }^{103}$

\section{A Supported Decision-Making for Restraint Decisions}

The ALRC reports that 'taking the National Decision-Making Principles into account in the context of restrictive practices would mean that, as far as possible, decisions about restrictive practices should ultimately be those of the person potentially subject to them'. ${ }^{104}$ Support should be directed at securing the person's will, preferences and rights in making the decision. This raises practical challenges for elderly people with dementia.

Restraint is commonly considered where cognitive decline is advanced and the ability of the person to make supported decisions will be limited. Supported decisions to enter a locked care facility or to accept physical or

(i) incapable of looking after his own health and safety;

(ii) unable to make reasonable judgments in respect of matters relating to his person; or

(iii) in need of oversight, care or control in the interests of his own health and safety or for the protection of others; and

(c) is in need of a guardian,

97 Ibid, s 43(1)(b)(iii).

98 Secretary, Department of Health and Community Services $v$ JWB and SMB (Marion's case) (1992) 175 CLR 218.

99 ALRC, Report No 124, above n 11, 64 (Principle 1).

100 Guardianship and Administration Act 1990 (WA) s 4(3).

101 Ibid, s 110ZJ.

102 Ibid, s 4(4)-(6).

103 ALRC, Report No 124, above n 11, 64 (Principle 2).

104 Ibid, 252. 
chemical restraint could be made in advance if the matter is raised early enough, but the emotional challenges in doing so for both the individual and the supporters should be acknowledged.

Advance consent to restraint also poses conceptual difficulties. If a person is able to consent to the deprivation of liberty then that carries with it the ability to refuse and to withdraw consent. If consent can be withdrawn for physical restraint then there is no restraint. An advance directive where the person agrees to restraint even if they later resist, such as that envisaged in the Powers of Attorney Act 1998 (Qld), ${ }^{105}$ gives meaning to the restraint but increases the challenges in terms of the individual's ability to understand what is proposed. This kind of Ulysses clause starkly raises the ethical challenges of conflicting critical interests and experiential interests particularly where the advance of dementia is accompanied with personality changes. ${ }^{106}$

Supported decision-making will be most effective where a person with limited decision-making capacity agrees with the views of those offering support. It is problematic where the individual disagrees with those views. Supported decision-making may be practical where chemical restraint is proposed, but it is difficult to envisage its operation for physical restraint where resistance is central to the perceived need for restraint. The fluctuating perception and memory of people with dementia exacerbates this problem. At some point supported decision-making would become a fiction.

The practice of supported decision-making seems to be most relevant to preventing the need for restraint. The ALRC suggests that communication support could help identify and address the reasons for challenging behaviour and avoid the need for restraint. ${ }^{107}$ The Support Guidelines provide that "persons who require decision-making support should be supported to participate in and contribute to all aspects of life'. ${ }^{108}$ Support should be directed at identifying and securing the person's preferences in adapting and interacting with the care environment.

Incorporating supported decision-making principles into the Commonwealth's Decision-making Tool: Supporting a Restraint Free Environment in Residential Aged Care is one option. ${ }^{109}$ However, in undertaking its recent inquiry into the care and management of people living with dementia, the Commonwealth Senate Community Affairs References Committee was surprised to find that "many people appear to be unaware that the Guidelines [the 2012 decision-making tools] exist, let alone what they contain'. ${ }^{110}$ To succeed, such an approach would need to be accompanied by education.

105 See, eg, Powers of Attorney Act 1998 (Qld) s 35(2).

106 Rebecca Dresser, 'Dworkin on Dementia: Elegant Theory, Questionable Policy' (1995) 25(6) Hastings Center Report 32.

107 ALRC, Report No 124, above n 11, 253.

108 Ibid, 69-77 (Recommendations 3-2).

109 Department of Health and Ageing, above n 20, 28.

110 Community Affairs References Committee, above n 12, [6.45]. 
An alternative approach would be to provide structure and principles for supported decision-making with statutory backing through reform to the GA Act. This should include arrangements for the formal appointment of supporters by the person themselves or by the State Administrative Tribunal, and should include rights to access confidential information where necessary to provide support. Proposals such as these have been implemented in British Columbia and recognise that a person may be able to choose a trusted representative even though they are not competent to make other decisions for themselves. ${ }^{111}$ Similar arrangements have been recommended and partially implemented in Victoria, ${ }^{112}$ and are being considered in Ontario. ${ }^{113}$ The $M H$ Act 2014 also offers guidance on how this might be done. $M H$ Act 2014 provides for a 'nominated person' to assist a person with mental illness to exercise their rights under the Act and have their wishes and interests taken into account. ${ }^{114}$ The Act also establishes a Charter of Mental Health Care Principles, Principle 14 of which requires mental health services to adopt a 'collaborative approach' to decision-making which includes respecting and facilitating the right of persons to involve family, carers and other support persons. ${ }^{115}$

\section{Substitute or Representative Decision-Making FOR RESTRAINT}

In Western Australia, clarity is required regarding who can make a decision to move a dementia patient into a locked ward and provide consent to restraints therein. Informal arrangements are currently adopted whereby a guardian, enduring guardian or the responsible person make this decision. However, as discussed above, the lawful basis for them to do so is unclear. The Victorian Law Reform Commission has taken the view that it is inappropriate for a responsible person to have the power to make decisions that involve deprivation of liberty because of the danger of conflict of interest. ${ }^{116}$ In addition, decisions that involve such a serious restriction on dignity and the right to liberty should not be made informally. On the other hand, an overly formal and bureaucratic approach will be costly and may impede effective care. Autonomy will be supported if people are able to choose for themselves who can make a restraint decision on their behalf, and empower their enduring guardian to do so. The State Administrative Tribunal should also be able to expressly empower an appointed guardian to make decisions that deprive the represented person

111 Representation Agreement Act, RSBC 1996.

112 Victorian Law Reform Commission, above n 12; Powers of Attorney Act 2014 (Vic) Pt 7.

113 Law Commission of Ontario, Legal Capacity, Decision-making and Guardianship, Discussion Paper (2014), Pt 3.

114 Mental Health Act 2014 (WA) s 263.

115 Ibid, ss 11, 12.

116 Victorian Law Reform Commission, above n 12, 338. 
of liberty. ${ }^{117}$ Formalising these arrangements through the provision of express statutory power in the GA Act would resolve the legal uncertainty, place care providers on a secure legal footing and clarify the immunity provided by the new s 584 of the $M H$ Act 2014 . It would also help ensure that decisions that involve the deprivation of liberty are treated with the seriousness they deserve.

Both the common law and the legislation in Western Australia require that substituted decision-makers exercise their powers by making the decision in the 'best interests' of the person. ${ }^{118}$ This is an objective test that involves weighing the benefits and detriments of the particular decision for the person. Although the wishes of the patient must be considered, this falls short of the requirements of the CRPD Art 12 and of Principle 3 of the National Decision-Making Principles, which requires that 'the will, preference and rights of persons who may require decision-making support must direct decisions that affect their lives'. The alternative substituted judgment approach, also known as facilitated decision-making, maximises autonomy by considering what decision the person would have made for themselves if they had been capable and is better aligned with Principle 3 and the CRPD. The adoption of this principle in the GA Act would ensure that restraint decisions by representatives are clearly focused on the will and rights of the person and the preferences they expressed in the past.

When restraint is proposed, clear principles are required that identify the criteria to be considered by decision makers. In this regard, the Commonwealth's Decision-making Tool: Supporting a Restraint Free Environment in Residential Aged Care provides an important framework for restraint decision-making in residential aged care facilities. ${ }^{119}$ The decision-making tool is guided by the principles of last resort and least restrictive alternative, advocating the adoption of restraint free options to deal with behaviours of concern and, only if these options are unsuccessful, 'it may be necessary to use the least restrictive form of restraint to ensure the safety and dignity of all concerned'. ${ }^{120}$ However, as noted above, many care providers are unaware of the tool. ${ }^{121}$ This lack of knowledge needs to be addressed. The ALRC's recommendation that a national approach be adopted to the use of restrictive practices in all settings, including aged care, might provide the impetus for clarifying and disseminating the criterion for restraint decisions. ${ }^{122}$ A legislative approach, such as that adopted in Queensland and Ontario, would ensure compliance with the National Decision-Making Principles. ${ }^{123}$

117 See, eg, Guardianship and Administration Act 2000 (Qld), Ch 5B, Pt 3.

118 GA Act ss 51, 110H, 110ZD(8).

119 Department of Health and Ageing, above n 20.

120 Ibid, 28.

121 Community Affairs References Committee, above n 12, [6.45].

122 ALRC, Report No 124, above n 11, 256.

123 Guardianship and Administration Act 2000 (Qld) Ch 5B: Long Term Care Homes Act, SO 2007 (Ontario) ss 29-36. 
Where guardians or next of kin are empowered to make these decisions, safeguards and oversight are also needed. To comply with Principle $4,{ }^{124}$ a mechanism is required to enable a dementia sufferer to challenge a restraint decision and all interventions must be subject to 'regular, independent and impartial monitoring and review'. ${ }^{25}$ The regime now in operation in the United Kingdom under the Mental Capacity Act 2005 (UK) requires authorisation and periodic review of decisions to detain a person in a hospital or care facility. ${ }^{126}$ This has been criticised as demanding and expensive ${ }^{127}$ and may be unnecessary where the decision-maker has been expressly empowered to make such a decision. However, some method of challenging such a decision is essential. A person who feels that they have been detained against their will and without proper justification must have a simple and easily accessible method of appeal. ${ }^{128}$ This could be achieved by inserting into the GA Act a right to appeal against a restraint decision to the State Administrative Tribunal, ${ }^{129}$ and providing for independent monitoring and review by Official Visitors or Dementia Advocates. In relation to the latter, the mental health legislative framework again presents a helpful model.

The Council of Official Visitors in Western Australia is tasked with visiting mental health facilities and ensuring that patients' rights are observed as well as investigating and resolving complaints. ${ }^{130}$ The $M H$ Act 2014 will, on commencement, create a new oversight service, the Mental Health Advocacy Service, to be headed by the Chief Mental Health Advocate. ${ }^{131}$ The functions of the Mental Health Advocates include assisting persons to access legal services, protect and enforce their rights and inquiring into, and attempting to resolve, complaints made by patients about care or treatment. ${ }^{132}$ A similar oversight body, separate from the Accreditation checks undertaken by inspectors of Commonwealth supported facilities, would provide independent monitoring and review, as well as assisting persons subject to restraint decisions to access an appeals process.

\section{Conclusion}

The growing number of older people with dementia, and the widespread use of different forms of restraint, raise concerns about the protection

124 ALRC, Report No 124, above n 11, 86.

125 Ibid, 87 (Recommendation 3-4 Safeguards Guidelines).

126 Mental Capacity Act 2005 (UK) Sch 1A, Hospital and Care Home Residents: Deprivation of Liberty.

127 Victorian Law Reform Commission, above n 12, 337; Michael Williams, John Chesterman and Richard Laufer, 'Consent versus Scrutiny: Restricting liberties in post-Bournewood Victoria' (2014) 21 Journal of Law and Medicine 641.

128 See, eg, Long Term Care Homes Act, SO 2007 (Ontario) s 32.

129 See, eg, Guardianship and Administration Act 2000 (Qld) s 80ZA.

130 Mental Health Act 1996 (Cth) ss 188, 190; see generally Pt 9.

131 Mental Health Act 2014 (Cth) Pt 20.

132 Ibid, s 352; see also the role of 'family councils' in Long Term Care Homes Act, SO 2007 (Ontario) s 60. 
of the autonomy and dignity of older people. It remains a complex challenge to craft laws and institutions that meet these concerns and ensure that elderly dementia sufferers receive the best care. ${ }^{133}$ Advances have been made in the provision of health care for dementia patients with the development of guidelines such as the Commonwealth Decision-making Tool: Supporting a Restraint Free Environment in Residential Care and the Users Rights Principles 2014 (Cth). ${ }^{134}$ However, the legal framework for restraint decisions remains unclear.

The current regime of decision-making for people who are cognitively impaired in Australian jurisdictions requires review in the light of the CRPD and the ALRC's 2014 report, Equality, Capacity and Disability in Commonwealth Law. ${ }^{135}$ Reform will be required to ensure that proper support is provided to maximise decision-making capacity for elders with declining cognitive ability. We have argued that restraint decisions expose the benefit and limitations of supported decision-making, and that the viability of supported decision-making models for restraint decisions needs to be carefully considered. Supported decision-making, especially supported communication, may help preserve the dignity of patients and reduce the need for restraint, however, with declining cognitive abilities, substituted or representative decision-making will ultimately be necessary. Where this occurs, we have argued that the 'best interest' paradigm of substituted decision-making must be replaced with a 'will and preferences' paradigm.

Restraint decisions are both very common and highly significant in terms of the loss of dignity, autonomy and liberty for persons with dementia. In spite of that, the legal framework in Western Australia remains unclear. Where restraint is proposed clear principles are required that:

- Identify and empower the best decision maker;

- Identify the criteria that must be considered by the decision maker; and

- Provide procedures for oversight and review that provide appropriate safeguards.

The current legal framework does not meet those objectives. We have argued that reform is required to ensure that people with dementia receive the care they need in a respectful and timely manner and that they are protected from abuse and unnecessary restriction of their liberty.

133 Terry Carney, 'Guardianship, "Social” Citizenship \& Theorising Substitute Decision-Making Law' in Israel Doron and Ann Soden (eds), Beyond Elder Law: New Directions in Law and Ageing (Springer, 2012) 14.

134 Department of Health and Ageing, above n 20.

135 ALRC, Report No 124, above n 11. 